\title{
Long-term follow-up of blood pressure and glomerular filtration rate in patients with a solitary functioning kidney: a comparison between Wilms tumor survivors and nephrectomy for other reasons
}

\author{
Annelies M. C. Mavinkurve-Groothuis ${ }^{1}$ • Frank van de Kracht $^{2,3}$ • Rik Westland ${ }^{4}$. \\ Joanna A. E. van Wijk ${ }^{4}$. Jacqueline J. Loonen ${ }^{2} \cdot$ Michiel F. Schreuder $^{3}$
}

Received: 24 May 2015 / Revised: 4 September 2015 / Accepted: 8 September 2015 / Published online: 19 October 2015

(C) The Author(s) 2015. This article is published with open access at Springerlink.com

\begin{abstract}
Background Children with unilateral Wilms tumor (WT) treated with chemotherapy and/or radiotherapy and nephrectomy have excellent survival rates. A solitary functioning kidney (SFK) is associated with progressive renal injury. This study aims to investigate the additional effect of Wilms tumor treatment on renal function compared with children with an SFK for non-oncological reasons.

Methods A single-center retrospective cohort study on the renal injury markers of 79 survivors of unilateral WT was performed and compared with a matched group of children with an SFK for non-oncological reasons. Mean age at followup was 12.4 (SD 5.9) years.

Results During follow-up, mean estimated glomerular filtration rate (eGFR) and blood pressure z-scores remained stable at an acceptable level. However, in the group of $31 \mathrm{WT}$ patients with a follow-up of 15 years, $23 \%$ showed signs of renal injury. This proportion was smaller than the $54 \%$ in a group of SFK patients based on non-oncological causes $(p=0.004)$
\end{abstract}

Michiel F. Schreuder

michiel.schreuder@radboudumc.nl

1 Princess Maxima Center for Pediatric Oncology, Utrecht, The Netherlands

2 Department of Pediatric Hematology and Oncology, Radboudumc Amalia Children's Hospital, Nijmegen, The Netherlands

3 Radboudumc Amalia Children's Hospital Department of Pediatric Nephrology 804, Radboud University Medical Center, PO Box 9101, 6500 HB Nijmegen, The Netherlands

4 Department of Pediatric Nephrology, VU University Medical Center, Amsterdam, The Netherlands
Conclusions A significant proportion of WT survivors develop renal injury during follow-up. Our data may be an underestimation of the true frequency of progressive renal injury, due to a lack of information on proteinuria. As with patients with a nononcological SFK, long-term follow-up is essential to monitor WT survivors.

Keywords Wilms tumor - Solitary functioning kidney · Glomerular hyperfiltration $\cdot$ Blood pressure $\cdot$ Proteinuria

\section{Introduction}

In recent years, it has become clear that a solitary functioning kidney (SFK) from birth or acquired during childhood leads to progressive renal injury $[1,2]$. In the Kidney of MONofunctional Origin (KIMONO) study cohort of over 400 children with an SFK, one in three children showed signs of progressive renal injury (hypertension, proteinuria, and/or drugs prescribed for either of the two indications) during childhood [1, 2]. As described by Brenner et al. [3], this is hypothesized to be based on glomerular hyperfiltration, which results in glomerular hypertension and damage. In addition, a long-term follow-up study of patients with an SFK showed that 20-50\% were dependent on renal replacement therapy at the age of 30 years [4]. These data illustrate that an SFK in childhood may have serious long-term consequences.

One of the reasons for an acquired SFK is a unilateral Wilms tumor (WT). It accounts for $6 \%$ of all childhood malignancies, with the highest incidence rate between 2 and 5 years of age, and a rare occurrence in adolescents or adults [5]. The outcome of patients with WT has significantly improved over the past decades. Five-year overall survival estimates now range from 80 to over $95 \%$, depending on the 
stage and histology [6-8]. Chemotherapy and radiotherapy may be harmful to the remaining kidney, but in general the decrease in renal function is believed to be temporary and reversible, and only present during chemotherapeutic treatment [9]. The hyperfiltration hypothesis can also be expected to apply in WT survivors. Green recently reviewed studies on renal dysfunction in WT survivors [9]. Unfortunately, these studies are small with heterogeneous patient populations and with different methods of measuring renal function. In addition, in most SFK follow-up studies, WT patients are excluded, which makes the long-term outcome of having an SFK after tumor nephrectomy together with chemo- and/or radiotherapy compared with SFK after non-oncological causes unknown. We hypothesize that children with an SFK after WT have a decreased renal outcome compared with non-WT postnephrectomy subjects, resulting in a higher rate of hypertension, proteinuria, and/or reduced glomerular filtration rate (GFR). This study aims to investigate the additional effect of WT treatment on long-term renal function compared with children with an SFK after nephrectomy for non-oncological reasons.

\section{Materials and methods}

\section{Patients}

All survivors of unilateral WT, diagnosed between 1987 and 2011 at the Radboud University Medical Center from whom follow-up data were available, were included in our study. Data were retrospectively collected at four set time-points, i.e., after 2.5, 5, 10, and 15 years of follow-up, and were compared with those of matched children with SFK for nononcological reasons from the KIMONO cohort [2]. Patients with a renal tumor other than WT were excluded from the study, as were patients with associated syndromes such as WAGR (WT, aniridia, genitourinary malformation, and mental retardation) and Denys-Drash syndrome.

\section{Data collection}

All data were collected from the patient records using a case record form. Tumor and treatment characteristics were collected from each patient. At diagnosis and at every follow-up time point, medical examination, laboratory and/or radiology data were recorded. During follow-up, standard medical examination and renal laboratory testing (serum creatinine, urine albumin-creatinine or protein-creatinine ratio or urine dipstick) were collected when available. Different methods of determining creatinine levels were used. Unfortunately, there were insufficient data on proteinuria and renal length to evaluate as a separate marker. When no data were available, these were considered to be within the normal range to prevent the overestimation of renal injury. The GFR was estimated (eGFR) using the revised Schwartz formula: eGFR $\left(\mathrm{ml} * \min ^{-1} * 1.73 \mathrm{~m}^{-2}\right)=k \times$ height $(\mathrm{m}) /$ serum creatinine [in $\mathrm{mg} / \mathrm{dL}]$ ), with a $\kappa$ value of 41.3 [10]. Blood pressure (BP) was measured using either a manual auscultatory or an automatic oscillometric device. Neither the method nor the device used was specified in the patient file. High BP was defined as systolic BP (SBP) and/or diastolic BP (DBP) values above the 95th percentile (z-score $>1.65$ ) adjusted for age, gender, and height [11]. Renal injury was defined as a reduced eGFR $\left(<60 \mathrm{ml}^{*} \mathrm{~min}^{-1} * 1.73 \mathrm{~m}^{-2}\right)$, proteinuria and/or high BP, and/ or drug use to treat either proteinuria and/or high BP [12].

\section{KIMONO cohort}

The KIMONO cohort comprises the worlds' largest cohort of patients with an SFK. From the entire cohort of over 400 patients, the patients with matching characteristics were selected (as far as possible). Criteria for the selection consisted of the type of diagnosis (acquired SFK mainly based on the nephrectomy of a previously functional kidney) and duration of follow-up $>10$ years.

\section{Statistical analysis}

All data were analyzed using SPSS Statistics 18.0 (SPSS, Chicago, IL, USA). Data were presented as number (\%) or mean (standard deviation, $\mathrm{SD}$ ). The BP z-scores were calculated using percentile scores [11]. Differences between measured $\mathrm{z}$-scores and expected $(\mathrm{z}$-score $=0)$ were calculated using the one sample $t$-test. Comparison in eGFR between different groups (gender, chemotherapy, disease stage) was performed using one-way ANOVA. Comparison between our cohort of WT survivors and the KIMONO cohort was carried out using the independent samples $t$ test. Statistical significance was set at $p<0.05$.

\section{Results}

\section{Patient characteristics}

We were able to identify 108 patients who have been treated for renal tumors at our institution. Figure 1 shows the inclusion criteria. Seven patients were excluded because of nonWilms renal tumor $(n=3$, clear cell sarcoma), bilateral WT $(n=3)$, and horseshoe kidney $(n=1)$. We were able to include 79 WT survivors in our study for whom follow-up details were available. Characteristics of the WT survivors and matched KIMONO subjects are shown in Table 1. 
Fig. 1 Patient inclusion criteria

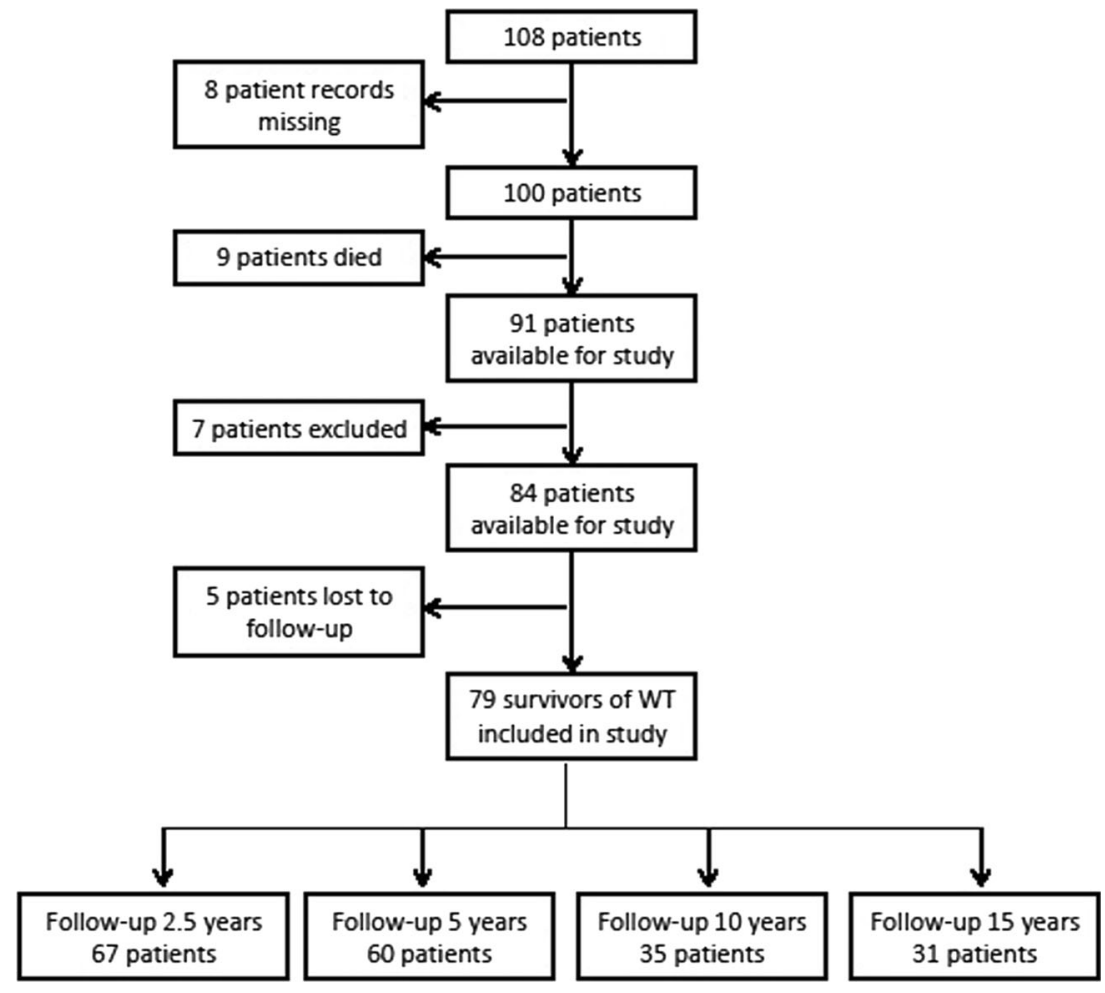

\section{Renal function of WT survivors}

Chart review of our WT survivors showed that renal functional analysis was mainly performed using SBP, DBP, and eGFR. Unfortunately, there was insufficient data on proteinuria. Table 2 shows renal function parameters of WT survivors at the different follow-up time points. At diagnosis, mean SBP zscore was 2.1 (SD 1.4) and DBP z-score was 1.8 (SD 1.3). At follow-up, blood pressure returned to normal values. At discharge from the hospital, mean SBP and DBP z-scores were 0.3 (SD 1.3) and 0.2 (SD 0.7) respectively. During follow-up, $\mathrm{BP}$ z-scores remained stable on average and none of the survivors used renoprotective drugs during follow-up. The eGFR remained stable over the follow-up period. There were no significant differences in eGFR within the different treatment protocols, gender or disease stage (data not shown), nor was there an effect of radiation therapy.

\section{Comparison with KIMONO study data}

We compared renal function of WT survivors with a matched group of SFK subjects from the KIMONO cohort (Table 3). Despite the matching, the KIMONO patients were younger than the WT survivors. The eGFR was similar in the cohort of WT survivors and the KIMONO cohort and no significant difference in SBP and DBP z-scores between the two cohorts was noted. However, progressive renal injury was more frequently found in the KIMONO cohort (54 \%) than in the WT survivors $(23 \%)$ after a follow-up of over 10 years.

\section{Discussion}

In this study, we showed that progressive renal injury in WT survivors with SFK occurs in a similar manner to that in children with SFK of non-oncological causes, even though the frequency may be lower. Recently, a large cohort of more than 400 children with SFK was evaluated for signs of progressive renal injury (KIMONO) [2]. We were able to compare a smaller cohort of WT survivors with a matched group from this KIMONO cohort. This comparison showed that there was a trend toward a higher frequency of high BP in the WT survivors. However, none of the WT survivors was treated with anti-hypertensive/anti-proteinuric drugs compared with $35 \%$ of the KIMONO cohort, which will have influenced the BP readings at follow-up. In addition, proteinuria and/or albuminuria was not tested in most WT survivors, whereas $44 \%$ of individuals in the KIMONO cohort were found to have proteinuria. These missing data may account for a large proportion of the difference in frequency of progressive renal injury between the two cohorts. Another explanation for the identified difference in renal injury may be the high prevalence of associated congenital anomalies of the kidney and urinary tract in patients from the KIMONO cohort. Indeed, it has been shown that these associated malformations are an independent risk factor for progressive renal injury [2]. Finally, a selection bias in the KIMONO cohort may have accounted for a larger than expected number of individuals with progressive renal injury. The KIMONO cohort may be considered a biased cohort, as not all patients were included after a prenatal 
Table 1 Characteristics of Wilms tumor survivors and subjects from the Kidney of MONo-functional Origin (KIMONO) cohort

\begin{tabular}{|c|c|c|c|}
\hline Patient characteristics & Wilms tumor & KIMONO & $p$ \\
\hline Number & 79 & 184 & \\
\hline Gender & & & 0.04 \\
\hline Male & $40(50 \%)$ & $118(64 \%)$ & \\
\hline Female & $39(50 \%)$ & $66(36 \%)$ & \\
\hline Age at nephrectomy (years) & 3.7 (SD 2.5) & $4.2(\mathrm{SD} 4.6)$ & 0.4 \\
\hline Age at latest follow-up (years) & $12.4(\mathrm{SD} 5.9)$ & $10.5(\mathrm{SD} 6.0)$ & 0.02 \\
\hline Follow-up duration (years) & $9.1(\mathrm{SD} 5.7)$ & $6.9(\mathrm{SD} 5.1)$ & 0.003 \\
\hline \multicolumn{4}{|l|}{ Side of tumor } \\
\hline Left & $44(56 \%)$ & & \\
\hline Right & $35(44 \%)$ & & \\
\hline \multicolumn{4}{|l|}{ Wilms tumor stage } \\
\hline I & $39(49 \%)$ & & \\
\hline II & $15(19 \%)$ & & \\
\hline III & $17(22 \%)$ & & \\
\hline IV & $8(10 \%)$ & & \\
\hline \multicolumn{4}{|l|}{ Histology at diagnosis } \\
\hline Low risk & $9(11 \%)$ & & \\
\hline Intermediate risk & $54(69 \%)$ & & \\
\hline High risk & $8(10 \%)$ & & \\
\hline \multicolumn{4}{|l|}{ Treatment protocol $^{\mathrm{a}}$} \\
\hline SIOP 9 & $13(17 \%)$ & & \\
\hline SIOP 93-01 & $31(39 \%)$ & & \\
\hline SIOP 2001 & $35(44 \%)$ & & \\
\hline Radiation therapy ${ }^{\mathrm{b}}$ & $19(24 \%)$ & & \\
\hline \multicolumn{4}{|c|}{ Reason for poor kidney function leading to nephrectomy } \\
\hline Congenital anomalies & & $32(18 \%)$ & \\
\hline Obstructive uropathy & & $41(22 \%)$ & \\
\hline Urinary tract infection & & $77(42 \%)$ & \\
\hline Posterior urethral valves & & $14(7 \%)$ & \\
\hline Miscellaneous & & $20(11 \%)$ & \\
\hline
\end{tabular}

Data are presented as mean (standard deviation, SD) or as a number (\%) SIOP International Society of Pediatric Oncology

${ }^{a}$ None of the patients was treated with ifosfamide

${ }^{\mathrm{b}}$ None of the patients received radiation therapy to the remaining kidney diagnosis, but may have been diagnosed based on clinical characteristics (e.g., recurrent urinary tract infections or a palpable abdominal mass). Even though previous analyses of such bias have not been shown to result in different conclusions, this has to be taken into account.

No difference in eGFR was found between the WT survivors and the KIMONO cohort. As most WT patients received drugs that were not directly nephrotoxic and the number of high-risk patients who received carboplatin was relatively small, this was in line with our expectations. The eGFR was not significantly different between the different treatment groups. However, subgroups of children treated with different chemotherapeutic drugs were small; therefore, we may have missed differences based on the sample size.

Green et al. recently reviewed the available evidence on progressive renal injury after successful treatment for ipsilateral nonsyndromic WT [6]. The risk of end-stage renal disease (ESRD) 20 years after diagnosis among children with unilateral, nonsyndromic WT treated according to the National Wilms Tumor Study Group protocols was $0.7 \%$ [13]. Progressive renal injury in WT survivors of a less serious degree is reported to be up to $30 \%$ in survivors without abdominal irradiation and up to $40 \%$ in WT survivors with abdominal irradiation. In a large cohort of adult survivors of different types of childhood cancer, low eGFR was associated with treatment with unilateral nephrectomy, abdominal radiation therapy, cisplatin, and ifosfamide [14]. Based on data from reports from recent years (Table 4), hypertension and albuminuria are found in $13 \%$ of WT survivors at latest follow-up, and $3 \%$ had a clinically relevant reduced GFR. As most reports do not describe a concurrence of renal injury markers, it may be estimated from the recent literature that progressive renal injury is found in $\pm 25 \%$ of WT survivors, which is in line with our results.

In daily pediatric care, equations that use creatinine to obtain an eGFR have been widely adopted by clinicians, as recommended by the Kidney Disease Outcome Quality Initiative (K/DOQI) guidelines [12]; however, it has several limitations compared with the gold standard measurement of GFR by inulin clearance [15]. Westland et al. examined the precision of six common estimating equations in predicting the gold standard GFR, determined by an inulin single-injection method, in children with an SFK [16]. They concluded that the combined

Table 2 Renal function of Wilms tumor survivors at the different follow-up time points

\begin{tabular}{|c|c|c|c|c|c|c|}
\hline & Diagnosis & Discharge & 2.5 years & 5 years & 10 years & 15 years \\
\hline Age (years) & $3.6(2.4)$ & $3.7(2.5)$ & $6.3(2.5)$ & $8.9(2.8)$ & $14.1(2.5)$ & $17.8(3.6)$ \\
\hline Systolic blood pressure (z-score) & $2.1(1.4)$ & $0.3(1.3)$ & $0.0(0.9)$ & $0.2(1.0)$ & $0.6(1.5)$ & $0.6(1.5)$ \\
\hline Diastolic blood pressure (z-score) & $1.8(1.3)$ & $0.2(0.7)$ & $0.8(1.0)$ & $0.1(0.6)$ & $0.0(0.7)$ & $0.0(0.7)$ \\
\hline eGFR $\left(\mathrm{ml}^{*} \min ^{-1} * 1.73 \mathrm{~m}^{-2}\right)$ & $90(36)$ & $86(21)$ & $86(25)$ & $89(23)$ & $82(22)$ & $83(14)$ \\
\hline
\end{tabular}

Data are presented as mean (standard deviation, SD)

$e G F R$ estimated glomerular filtration rate 
Table 3 Renal function of Wilms tumor survivors at a follow-up of 15 years compared with the KIMONO cohort

\begin{tabular}{|c|c|c|c|}
\hline & Wilms tumor & KIMONO & $p$ \\
\hline Number & 31 & 57 & \\
\hline Age & $17.8(\mathrm{SD} 3.6)$ & $15.4(\mathrm{SD} 2.9)$ & 0.002 \\
\hline Systolic blood pressure (z-score) & $0.7(\mathrm{SD} 1.5)$ & $0.3(\mathrm{SD} 1.1)$ & 0.3 \\
\hline Diastolic blood pressure (z-score) & $0.0(\mathrm{SD} 0.7)$ & $0.0(\mathrm{SD} 0.8)$ & 0.9 \\
\hline High blood pressure & $6 / 23(26 \%)$ & $6 / 57(11 \%)$ & 0.08 \\
\hline eGFR $\left(\mathrm{ml}^{*} \min ^{-1} * 1.73 \mathrm{~m}^{-2}\right)$ & $83(\mathrm{SD} 14)$ & 89 (SD 31) & 0.2 \\
\hline eGFR $<60 \mathrm{ml}^{*} \min ^{-1} * 1.73 \mathrm{~m}^{-2}$ & $1 / 24(4 \%)$ & $7 / 57(12 \%)$ & 0.3 \\
\hline Proteinuria & ND & $25 / 57(44 \%)$ & \\
\hline Anti-hypertensive and/or anti-proteinuric drug use & $0 / 31(0 \%)$ & $20 / 57(35 \%)$ & $<0.001$ \\
\hline Renal injury & $7 / 31(23 \%)$ & $31 / 57(54 \%)$ & 0.004 \\
\hline
\end{tabular}

Renal injury was defined as high blood pressure, proteinuria, and/or the use of drugs treating either condition, and/or eGFR $<60 \mathrm{ml}^{*} \mathrm{~min}^{-1} * 1.73 \mathrm{~m}^{-2}$

Data are presented as mean (standard deviation, SD) or as number (\%)

eGFR estimated glomerular filtration rate, $N D$ not determined serum cystatin C/serum creatinine/blood urea nitrogen (BUN) Chronic Kidney Disease in Children (cKiD) equation estimates the GFR of children with an SFK with superior precision. However, when cystatin C is not available, eGFR-Schwartz is an acceptable alternative. In most studies reporting on progressive renal injury in WT survivors, GFR has been estimated using the Schwartz equation, as in our study. Different cut-off values of eGFR are used to define renal injury. Green et al. [6] used an eGFR of $<80 \mathrm{ml}^{*} \min ^{-1} * 1.73 \mathrm{~m}^{-2}$ to define renal injury, whereas we used an eGFR of $<60 \mathrm{ml}^{*} \min ^{-1} * 1.73 \mathrm{~m}^{-2}$, as was recommended by the clinical practice guidelines for chronic kidney disease in children and adolescents [12]. However, it must be noted that the decline in eGFR due to glomerular hyperfiltration is a relatively late phenomenon [17]. To detect early deterioration in eGFR, it would therefore be interesting to investigate more sensitive renal markers (such as fibroblast growth factor [FGF] 23) in WT survivors during follow-up.

With excellent survival rates of WT patients reaching $90 \%$, the identification and prevention of late effects due to treatment are increasingly important. Life-long monitoring of WT survivors based on the knowledge of the present study and of previously described studies is warranted.

Nephron-sparing surgery (NSS) in unilateral WT patients could potentially diminish progressive renal injury because of the loss of nephrons [18]. Upfront chemotherapy and NSS have been shown to provide safe and effective oncological control, while optimizing renal function in patients with bilateral WT $[19,20]$. Hubertus et al. showed that hypertension is less common in patients with bilateral WT after bilateral NSS. At the same time, rates of local relapse or disease-associated

Table 4 Frequency of progressive renal injury at the latest follow-up in Wilms tumor survivors based on published cohorts since 2005

\begin{tabular}{|c|c|c|c|c|c|c|c|}
\hline & Number & $\begin{array}{l}\text { Follow up duration } \\
\text { (years) }\end{array}$ & Hypertension & $\begin{array}{l}\text { Albuminuria or } \\
\text { proteinuria }\end{array}$ & $\begin{array}{l}\text { Medication } \\
\text { use }\end{array}$ & $\begin{array}{l}\mathrm{eGFR}<60 \mathrm{ml}^{*} \min ^{-1} * \\
1.73 \mathrm{~m}^{-2}\end{array}$ & $\begin{array}{l}\text { Renal injury* } \\
\text { overall }\end{array}$ \\
\hline Cozzi et al. 2005 [28] & 16 & $6.0(\mathrm{SD} 3.4)$ & $2 / 16(12.5 \%)$ & $2 / 16(12.5 \%)$ & NR & NR & NR \\
\hline Daw et al. 2009 [29] & 11 & 11.2 & 2/11 (18.2\%) & $2 / 11(18.2 \%)$ & NR & NR & NR \\
\hline Stefanowicz et al. 2011 [30] & 32 & 9.3 (SD 5.4) & $2 / 32(6.3 \%)$ & $7 / 32(21.9 \%)$ & $0 / 32$ & $0 / 32$ & NR \\
\hline Sanpakit et al. 2013 [31] & 17 & 4.8 & $\mathrm{NR}$ & $\mathrm{NR}$ & NR & 2/17 (11.8\%) & NR \\
\hline Elli et al. 2013 [32] & 25 & 9.9 & $3 / 15(20.0 \%)$ & NR & $0 / 25$ & $0 / 25$ & NR \\
\hline Kern et al. 2014 [33] & 55 & 6.3 & NR & NR & NR & $2 / 55(3.6 \%)$ & NR \\
\hline Spreafico et al. 2014 [34] & 15 & 13.3 & $0 / 15$ & $2 / 15$ & NR & $0 / 15$ & NR \\
\hline Kishore et al. 2015 [35] & 29 & $4.8(\mathrm{SD} 2.6)$ & $2 / 29(6.9 \%)$ & $1 / 29(3.4 \%)$ & NR & $1 / 29(3.4 \%)$ & NR \\
\hline Current report & 31 & 14.8 (SD 3.3) & $6 / 23(26.1 \%)$ & NR & $0 / 31$ & $1 / 24(4.2 \%)$ & $7 / 31(22.6 \%)$ \\
\hline Overall & 231 & & $17 / 141(12.1 \%)$ & $14 / 103(13.6 \%)$ & $0 / 88$ & $6 / 197(3.0 \%)$ & \\
\hline
\end{tabular}

eGFR estimated glomerular filtration rate, $N R$ not reported

${ }^{a}$ Renal injury was defined as a reduced eGFR $\left(<60 \mathrm{ml}^{*} \min ^{-1} * 1.73 \mathrm{~m}^{-2}\right)$, proteinuria/albuminuria, and/or hypertension, and/or drug use to treat either proteinuria and/or hypertension 
Table 5 Opinion-based recommendation for the clinical follow-up of Wilms tumor survivors with a solitary functioning kidney

\begin{tabular}{|c|c|c|}
\hline & $\begin{array}{l}\text { No progressive } \\
\text { renal injury }\end{array}$ & $\begin{array}{l}\text { eGFR }<60 \mathrm{ml}^{*} \min ^{-1} * 1.73 \mathrm{~m}^{-2} \\
\text { and/or medication for } \\
\text { proteinuria/hypertension }\end{array}$ \\
\hline Blood pressure & Once yearly & 2-4/year \\
\hline Albuminuria & Once yearly & 2-4/year \\
\hline Serum creatinine/GFR & Every 5 years & 2-4/year \\
\hline
\end{tabular}

24-h ambulatory blood pressure measurement is preferred in children and adults

Albuminuria may be estimated through the urinary albumin-to-creatinine ratio and should be determined in a first fresh morning sample (normal value $<30 \mathrm{mg} / \mathrm{g}$ )

GFR can be estimated using the commonly used Schwartz formula (see Materials and methods)

Last ultrasound to be performed at 15-16 years of age

$e G F R$ estimated glomerular filtration rate

death were equal to those of patients with bilateral WT and unilateral NSS and contralateral nephrectomy, suggesting NSS to be oncologically safe [21]. A recent Surveillance, Epidemiology, and End Results (SEER) analysis on the use of NSS and the impact on survival in children with WT also concluded that overall survival was similar between NSS and radical nephrectomy in a cohort of both bilateral and unilateral WT patients [22]. Cost et al. compared renal function outcomes after NSS and radical nephrectomy in nonsyndromic unilateral WT patients only. EGFR at last follow-up was equal in the two groups [23]. Data from the Internatioanal Society of Pediatric Oncology (SIOP) 2001 study showed that NSS was only performed in $3 \%$ of patients with unilateral WT ( $65 \%$ in stage I tumors). The authors concluded that despite excellent survival with few relapses, the gain of nephrons needs to be weighed against the risk of inducing stage III with intensified therapy [24]. Studies on renal function after NSS are based on relatively small patient groups and are all of a retrospective nature. Larger prospective studies are needed to fully address the gain of renal function versus oncological outcome in NSS.

Preserving renal function may serve another important goal, namely preventing cardiovascular complications. Cardiorenal syndrome is defined as a pathological disorder of the heart and kidneys in which acute or chronic dysfunction in one organ may induce acute or chronic dysfunction in the other organ. It includes a broad spectrum of diseases in which the heart and kidney are both involved [25]. Patients with chronic kidney disease are at a higher risk of mortality than the general population. The renal dysfunction represents an independent risk factor for cardiovascular disease, as these patients present higher mortality rates for myocardial infarction and sudden death [26, 27].

Our study has several limitations. First of all, our study has a retrospective design. As a pre-defined follow-up schedule has only been implemented in the last few years, data were missing from a different number of patients at each time-point. In addition, some data were retrieved from other hospitals, where other methods and reference values may have been used. BP was measured manually at the beginning of the study period, and by using oscillometric methods (DynaMap) for the last few years. Unfortunately, information on the method of measurement is not mentioned in the patient record, which may have an effect on the results. In addition, BP used to be measured only once, whereas it is measured three times in the current follow-up protocol. Analogous to the guideline that was presented for children with an SFK [17], we suggest a similar follow-up protocol for WT survivors with an SFK (Table 5).

\section{Conclusion}

In a similar fashion to children with an SFK for non-oncological reasons, progressive renal injury presents in WT survivors, but the incidence is lower. However, renal injury in our cohorts may have been underestimated owing to the absence of information on proteinuria in WT survivors. As with patients with a nonmalignant SFK, long-term follow-up is essential to monitor, inform, and prevent disease sequelae for WT survivors. A standardized follow-up protocol (including urinalysis) has been put in place to optimize follow-up.

Sources of support This study was not funded.

Conflict of interest The authors declare that they have no conflict of interest.

Open Access This article is distributed under the terms of the Creative Commons Attribution 4.0 International License (http:// creativecommons.org/licenses/by/4.0/), which permits unrestricted use, distribution, and reproduction in any medium, provided you give appropriate credit to the original author(s) and the source, provide a link to the Creative Commons license, and indicate if changes were made.

\section{References}

1. Westland R, Schreuder MF, Bökenkamp A, Spreeuwenberg MD, van Wijk JA (2011) Renal injury in children with a solitary functioning kidney - the KIMONO study. Nephrol Dial Transplant 26: 1533-1541

2. Westland R, Kurvers RA, van Wijk JA, Schreuder MF (2013) Risk factors for renal injury in children with a solitary functioning kidney. Pediatrics 131:e478-e485

3. Brenner BM, Lawler EV, Mackenzie HS (1996) The hyperfiltration theory: a paradigm shift in nephrology. Kidney Int 49:1774-1777

4. Sanna-Cherchi S, Ravani P, Corbani V, Parodi S, Haupt R, Piaggio G, Innocenti ML, Somenzi D, Trivelli A, Caridi G, Izzi C, Scolari F, Mattioli G, Allegri L, Ghiggeri GM (2009) 
Renal outcome in patients with congenital anomalies of the kidney and urinary tract. Kidney Int 76:528-533

5. Davidoff AM (2009) Wilms tumor. Curr Opin Pediatr 21:357-364

6. Green DM, Breslow NE, D'Angio GJ, Malogolowkin MH, Ritchey ML, Evans AE, Beckwith JB, Perlman EJ, Shamberger RC, Peterson S, Grundy PE, Dome JS, Thomas PR, Kalapurakal JA (2014) Outcome of patients with stage II/favorable histology Wilms tumor with and without local tumor spill: a report from the National Wilms Tumor Study Group. Pediatr Blood Cancer 61: 134-139

7. Breslow N, Sharples K, Beckwith JB, Takashima J, Kelalis PP, Green DM, D'Angio GJ (1991) Prognostic factors in nonmetastatic, favorable histology Wilms tumor. Results of the Third National Wilms Tumor Study. Cancer 68:2345-2353

8. Graf N, van Tinteren H, Bergeron C, Pein F, van den HeuvelEibrink MM, Sandstedt B, Schenk JP, Godzinski J, Oldenburger F, Furtwängler R, de Kraker J (2012) Characteristics and outcome of stage II and III non-anaplastic Wilms tumour treated according to the SIOP trial and study 93-01. Eur J Cancer 48:3240-3248

9. Green DM (2013) Evaluation of renal function after successful treatment for unilateral, non-syndromic Wilms tumor. Pediatr Blood Cancer 60:1929-1935

10. Schwartz GJ, Muñoz A, Schneider MF, Mak RH, Kaskel F, Warady BA, Furth SL (2009) New equations to estimate GFR in children with CKD. J Am Soc Nephrol 20:629-637

11. National High Blood Pressure Education Program Working Group on High Blood Pressure in Children and Adolescents (2004) The fourth report on the diagnosis, evaluation, and treatment of high blood pressure in children and adolescents. Pediatrics 114:555-576

12. Hogg RJ, Furth S, Lemley KV, Portman R, Schwartz GJ, Coresh J, Balk E, Lau J, Levin A, Kausz AT, Eknoyan G, Levey AS, National Kidney Foundation's Kidney Disease Outcomes Quality Initiative (2003) National Kidney Foundation's Kidney Disease Outcomes Quality Initiative clinical practice guidelines for chronic kidney disease in children and adolescents: evaluation, classification, and stratification. Pediatrics 111:1416-1421

13. Lange J, Peterson SM, Takashima JR, Grigoriev Y, Ritchey ML, Shamberger RC, Beckwith JB, Perlman E, Green DM, Breslow NE (2011) Risk factors for end stage renal disease in non-WT1syndromic Wilms tumor. J Urol 186:378-386

14. Blijdorp K, Dekkers IA, Cransberg K, Pluijm SMF, Pieters R, van den Heuvel-Eibrink MM, Neggers SJCMM (2013) Long-term nephrotoxicity in adult survivors of childhood cancer. Clin J Am Soc Nephrol 8:922-929

15. Van Rossum LK, Mathot RA, Cransberg K, Vulto AG (2003) Optimal sampling strategies to assess inulin clearance in children by the inulin single-injection method. Clin Chem 49: 1170-1179

16. Westland R, Abraham Y, Bökenkamp A, Stoffel-Wagner B, Schreuder MF, van Wijk JA (2013) Precision of estimating equations for GFR in children with a solitary functioning kidney: the KIMONO study. Clin J Am Soc Nephrol 8:764-772

17. Westland R, Schreuder MF, van Goudoever JB, Sanna-Cherchi S, van Wijk JA (2014) Clinical implications of the solitary functioning kidney. Clin J Am Soc Nephrol 9:978-986

18. Cozzi DA, Ceccanti S, Frediani S, Mele E, Cozzi F (2013) Renal function adaptation up to the fifth decade after treatment of children with unilateral renal tumor: a cross-sectional and longitudinal study. Pediatr Blood Cancer 60:1534-1538

19. Kieran K, Williams MA, Dome JS, McGregor LM, Krasin MJ, Davidoff AM (2013) Margin status and tumor recurrence after nephron-sparing surgery for bilateral Wilms tumor. J Pediatr Surg 48:1481-1485
20. Kieran K, Williams MA, McGregor LM, Dome JS, Krasin MJ, Davidoff AM (2014) Repeat nephron-sparing surgery for children with bilateral Wilms tumor. J Pediatr Surg 49:149-153

21. Hubertus J, Günther B, Becker K, Graf N, Furtwängler R, Ferrari R, Gruhn B, Stahl R, von Schweinitz D, Stehr M (2015) Development of hypertension is less frequent after bilateral nephron sparing surgery for bilateral Wilms tumor in a long-term survey. J Urol 193: 262-266

22. Wang HH, Abern MR, Cost NG, Chu DI, Ross SS, Wiener JS, Routh JC (2014) Use of nephron sparing surgery and impact on survival in children with Wilms tumor: a SEER analysis. J Urol 192:1196-1202

23. Cost NG, Sawicz-Birkowska K, Kajbafzadeh AM, Tourchi A, Parigi GB, Guillén G, DeFoor WR Jr, Apoznanski W (2014) A comparison of renal function outcomes after nephron-sparing surgery and radical nephrectomy for nonsyndromic unilateral Wilms tumor. Urology 83:1388-1393

24. Wilde JC, Aronson DC, Sznajder B, Van Tinteren H, Powis M, Okoye B, Cecchetto G, Audry G, Fuchs J, Schweinitz DV, Heij H, Graf N, Bergeron C, Pritchard-Jones K, Van Den Heuvel-Eibrink M, Carli M, Oldenburger F, Sandstedt B, De Kraker J, Godzinski J (2014) Nephron sparing surgery (NSS) for unilateral Wilms tumor (UWT): The SIOP 2001 experience. Pediatr Blood Cancer 61:2175-2179

25. Di Lullo L, House A, Gorini A, Santoboni A, Russo D, Ronco C (2015) Chronic kidney disease and cardiovascular complications. Heart Fail Rev 20:259-272

26. Selby NM, Kolhe NV, McIntyre CW, Monaghan J, Lawson N, Elliott D, Packington R, Fluck RJ (2012) Defining the cause of death in hospitalised patients with acute kidney injury. PLoS One 7:e48580

27. Kumar S, Bogle R, Banerjee D (2014) Why do young people with chronic kidney disease die early? World J Nephrol 3:143-155

28. Cozzi F, Schiavetti A, Morini F, Zani A, Gambino M, Donfrancesco C, Cozzi DA (2005) Renal function adaptation in children with unilateral renal tumors treated with nephron sparing surgery or nephrectomy. J Urol 174:1404-1408

29. Daw NC, Gregornik D, Rodman J, Marina N, Wu J, Kun LE, Jenkins JJ, McPherson V, Wilimas J, Jones DP (2009) Renal function after ifosfamide, carboplatin and etoposide (ICE) chemotherapy, nephrectomy and radiotherapy in children with Wilms tumour. Eur J Cancer 45:99-106

30. Stefanowicz J, Kosiak M, Romanowicz G, Owczuk R, Adamkiewicz-Drożyńska E, Balcerska A (2011) Glomerular filtration rate and prevalence of chronic kidney disease in Wilms tumour survivors. Pediatr Nephrol 26:759-766

31. Sanpakit K, Triwatanawong J, Sumboonnanonda A (2013) Longterm outcome in pediatric renal tumor survivors: experience of a single center. J Pediatr Hematol Oncol 35:610-613

32. Elli M, Sungur M, Genç G, Ayyildiz P, Dagdemir A, Pinarli FG, Acar S (2013) The late effects of anticancer therapy after childhood Wilm's tumor: the role of diastolic function and ambulatory blood pressure monitoring. Jpn J Clin Oncol 43:1004-1011

33. Kern AJ, Inouye B, Ko JS, Gorin MA, Allaf ME, Goldstein S, DiCarlo HN, Shah BB, Wang MH (2014) Impact of nephrectomy on long-term renal function in non-syndromic children treated for unifocal Wilms tumor. J Pediatr Urol 10:662-666

34. Spreafico F, Terenziani M, Testa S, Perotti D, Collini P, Piva L, Ardissino G (2014) Long-term renal outcome in adolescent and young adult patients nephrectomized for unilateral Wilms tumor. Pediatr Blood Cancer 61:1136-1137

35. Kishore SS, Oberoi S, Bhattacharya A, Prasad R, Trehan A, Bansal D, Marwaha RK (2015) Function and size of the residual kidney after treatment of Wilms tumor. Pediatr Hematol Oncol 32:11-17 